\title{
Sorghum bicolor Supplement
}

National Cancer Institute

\section{Source}

National Cancer Institute. Sorghum bicolor Supplement. NCI Thesaurus. Code C111681.

An herbal-based nutritional supplement containing the leaf sheaths of the plant Sorghum bicolor, with potential antioxidant, anti-inflammatory, chemopreventive and immunomodulating activities. Sorghum bicolor supplement contains various phytochemicals, including phenolic acids and polyphenols such as proanthocyanidins. Sorghum bicolor supplement is particularly rich in 3-deoxyanthocyanins, such as luteolinidin and apigeninidin, and appears to induce apoptosis and inhibit cell proliferation in cancer cells through the stimulation of various apoptosis promoter genes and the downregulation of certain apoptosis inhibitor genes. In addition, due to the strong antioxidant nature of the phytochemicals, these compounds are able to scavenge free radicals and prevent tissue damage. Also, intake of this supplement modulates the immune system by both increasing the activity of natural killer (NK) cells and initiating the activation of macrophages. 